\title{
Part I: Pathogenetic Role of Peroxynitrite in the Development of Diabetes and Diabetic Vascular Complications: Studies With FP15, A Novel Potent Peroxynitrite Decomposition Catalyst
}

\author{
Csaba Szabó, ${ }^{1,2}$ Jon G. Mabley, ${ }^{1}$ Suzanne M. Moeller, ${ }^{3}$ Roman Shimanovich, ${ }^{3}$ Pál Pacher, ${ }^{1}$ László \\ Virág, ${ }^{1}$ Francisco G. Soriano, ${ }^{2}$ John H. Van Duzer, ${ }^{1}$ William Williams, ${ }^{1}$ Andrew L. Salzman, ${ }^{1}$ and \\ John T. Groves ${ }^{3}$ \\ ${ }^{1}$ Inotek Pharmaceuticals Corporation, Beverly, Massachusetts, USA \\ ${ }^{2}$ Department of Surgery, New Jersey Medical School, University of Medicine and Dentistry New Jersey, \\ Newark, New Jersey, USA \\ ${ }^{3}$ Department of Chemistry, Princeton University, Princeton, New Jersey, USA \\ Accepted August 21, 2002. Contributed by C. Szabó
}

\begin{abstract}
Background: Peroxynitrite is a cytotoxic oxidant formed from nitric oxide (NO) and superoxide. Tyrosine nitration, a footprint of peroxynitrite, has been demonstrated in the pancreatic islets as well as in the cardiovascular system of diabetic subjects. Delineation of the pathogenetic role of peroxynitrite in disease conditions requires the use of potent, in vivo active peroxynitrite decomposition catalysts. The aim of the current work was to produce a potent peroxynitrite decomposition catalyst and to test its effects in rodent models of diabetes and its complications.

Methods: FP15 was synthesized and analyzed using standard chemical methods. Diabetes was triggered by the administration of streptozotocin. Tyrosine nitration was measured immunohistochemically. Cardiovascular and vascular measurements were conducted according to standard physiologic methods.

Results: FP15, a potent porphyrinic peroxynitrite
\end{abstract} decomposition catalyst, potently inhibited tyrosine ni- tration and peroxynitrite-induced cytotoxicity in vitro and in vivo. FP15 treatment $(3-10 \mathrm{mg} / \mathrm{kg} / \mathrm{d})$ dose dependently and reduced the incidence and severity of diabetes mellitus in rats subjected to multiple low doses of streptozotocin, as well as in nonobese mice developing spontaneous autoimmune diabetes. Furthermore, treatment with FP15 protected against the development of vascular dysfunction (loss of endothelium-dependent relaxations) and the cardiac dysfunction (loss of myocardial contractility) in diabetic mice. FP15 treatment reduced tyrosine nitration in the diabetic pancreatic islets.

Conclusions: The current results demonstrate the importance of endogenous peroxynitrite generation in the pathogenesis of autoimmune diabetes and diabetic cardiovascular complications. Peroxynitrite decomposition catalysts may be of therapeutic utility in diabetes and other pathophysiologic conditions.

\section{Introduction}

Peroxynitrite, the cytotoxic reaction products of nitric oxide (NO) and superoxide (1), acts as a terminal mediator of cellular injury in various pathophysiologic conditions. Peroxynitrite is able to induce cell necrosis and apoptosis (1-5). Typical cytotoxic reaction pathways triggered by peroxynitrite include lipid peroxidation, DNA breakage and base modification, activation of the nuclear enzyme poly(ADP-ribose) polymerase, as well as tyrosine nitration (1-8). Detection of this latter reaction is frequently being employed as a footprint for the formation of peroxynitrite in vivo.

Tyrosine nitration has been demonstrated in a variety of pathophysiologic conditions $(9,10)$, including diabetes mellitus (9-13). In the pancreatic islets of

Address correspondence and reprint requests to: John T Groves, Department of Chemistry, Princeton University, Princeton, NJ 08544-1009. Phone: (609) 258-3593; fax: (609) 258-0348; e-mail: jtgroves@princeton.edu. spontaneous autoimmune diabetic mice, a significant increase in tyrosine nitration was found and the degree of beta-cell destruction showed a good correlation with the frequency of nitrotyrosine-positive beta cells (10). It was therefore proposed that the intra-islet formation of peroxynitrite plays an active pathogenic role in the pathogenesis of diabetes mellitus (10). The observation that nitrotyrosine formation is present in the cardiovascular system (heart and blood vessels) of diabetic animals and humans (11-13), coupled with the fact that exposure of blood vessels of heart preparations to peroxynitrite leads to vascular and cardiac dysfunction (14-17), led to the suggestion that peroxynitrite may play an active role in the pathogenesis of diabetic cardiovascular failure. A direct demonstration of the pathogenetic role of peroxynitrite requires pharmacologic tools that have the ability to powerfully neutralize peroxynitrite in vivo. Here we describe the synthesis and characterization of FP15, a potent and in vivo 
active peroxynitrite decomposition catalyst. Using FP15, we provide direct evidence for the pathogenetic role of peroxynitrite in diabetic islet cell destruction, as well as in diabetic cardiovascular dysfunction.

\section{Methods}

Chemical Synthesis and In Vitro Characterization of the Compounds

Meso-tetra-2-pyridylporphyrin (2-PyP) was synthesized from pyrrole and pyridine 2-carboxaldehyde or purchased from Mid-Century Chemicals. Triethylene glycol monomethyl ether (95\%), ptoluenesulfonyl chloride $(99 \%+)$, triethylamine, ammonium hexafluorophosphate, ferrous ammonium sulfate hexahydrate, and tetrabutylammonium chloride were obtained from Aldrich. Dimethylformamide, anhydrous titration grade, was obtained from Acros. Sephadex LH-20 was purchased from Amersham Pharmacia Biotech. Bio-Rad AGIX8 ion-exchange resin $\left(\mathrm{Cl}^{-}\right.$form) was purchased from Bio-Rad.

Synthesis of Triethylene Glycol Monomethyl Ether Tosylate Triethylene glycol monomethyl ether $\mathbf{5 . 0}$ g) was dissolved in $100 \mathrm{ml}$ of freshly distilled $\mathrm{CH}_{2} \mathrm{Cl}_{2}$ and $6.21 \mathrm{~g}(2 \mathrm{eq})$ triethylamine was added. The reaction mixture was cooled in ice, and $7.55 \mathrm{~g}$ of (1.3 eq) $p$-toluene sulfonyl chloride was added all at once. The mixture was stirred overnight after the ice melted. The reaction mixture was filtered to remove triethylamine hydrochloride and the solvent was stripped. The residue was taken up in $75 \mathrm{ml}$ ethyl acetate, and it was washed with $75 \mathrm{ml}$ sat $\mathrm{NaHCO}_{3}$, then $75 \mathrm{ml} \mathrm{l} \mathrm{M} \mathrm{KHSO}{ }_{4}$, then $75 \mathrm{ml}$ sat $\mathrm{NaHCO}_{3}$. The organic layer was dried over $\mathrm{Na}_{2} \mathrm{SO}_{4}$ and the solvent was removed by distillation. The clear liquid residue was chromatographed on silica gel in 3:7 EtOAc/ $\mathrm{CH}_{2} \mathrm{Cl}_{2}$ to yield $7.05 \mathrm{~g}$ tosylate as a viscous oil $\left(73 \%\right.$ yield). ${ }^{1} \mathrm{H}$ NMR $\left(\mathrm{CDCl}_{3}\right): \delta 2.43(\mathrm{~s}, 3 \mathrm{H}$, $\left.\mathrm{PhCH}_{3}\right) \delta 3.35\left(\mathrm{~s}, 3 \mathrm{H}, \mathrm{OCH}_{3}\right) \delta 3.50-3.53(\mathrm{t}, 2 \mathrm{H}$, $\left.\mathrm{CH}_{3} \mathrm{OCH}_{2} \mathrm{CH}_{2}\right) \delta$ 3.57-3.61 (t, $\left.2 \mathrm{H}, \mathrm{CH}_{3} \mathrm{OCH}_{2} \mathrm{CH}_{2}\right)$ $\delta 3.56-3.59\left(\mathrm{br} \mathrm{s}, 4 \mathrm{H},-\mathrm{OCH}_{2} \mathrm{CH}_{2}^{-}\right) \delta 3.65-3.68(\mathrm{t}, 2 \mathrm{H}$, $\mathrm{CH}_{2} \mathrm{CH}_{2}$-OTs, $\left.\mathrm{J}=4.6 \mathrm{~Hz}\right) \delta 4.13-4.16\left(\mathrm{t}, 2 \mathrm{H}, \mathrm{CH}_{2} \mathrm{CH}_{2}-\right.$ OTs, $\mathrm{J}=4.6 \mathrm{~Hz}) \delta 7.35-7.38(\mathrm{~d}, 2 \mathrm{H}$, aromatic, $\mathrm{J}=8.07)$ $\delta$ 7.80-7.83 $(\mathrm{d}, 2 \mathrm{H}$, aromatic, $\mathrm{J}=8.07)$.

Synthesis of Tetrakis-2-(Triethylene Glycol Monomethyl Ether) Pyridyl Porphyrin To an oven-dried flask under argon was added $100 \mathrm{mg}$ of meso-2-pyridyl porphyrin (Mid-Century), $2 \mathrm{~g}$ of tosylate, and $1.5 \mathrm{ml}$ of dry dimethylformamide. The mixture was heated at $100{ }^{\circ} \mathrm{C}$ for $2-3$ days, until an aliquot of reaction mixture partitioned between water and chloroform showed no color in the chloroform layer. Complete alkylation was confirmed by the shift in maximum absorbance of the porphyrin from $\lambda=412$ to $\lambda=418 \mathrm{~nm}$. The reaction mixture was cooled and added dropwise to stirred ether, and the porphyrin precipitated as a purple gum. This gum was taken up in water, and a saturated solution of ammonium hexafluorophosphate added dropwise precipitated the porphyrin. The hexafluorophosphate salt could be precipitated from acetone with tetrabutylammonium chloride to yield the chloride salt of the porphyrin as a hygroscopic solid. It was purified by size exclusion chromatography on Sephadex LH-20. Yields ranged from $70-80 \%$, and degree of alkylation was confirmed by electrospray mass spectrometry.

${ }^{1} \mathrm{H}$ NMR is complex, as four unresolvable atropisomers form during alkylation.

${ }^{1} \mathrm{H}$ NMR $\left(\mathrm{CD}_{3} \mathrm{OD}\right): \delta 3.0-3.6\left(\mathrm{~m}, 13 \mathrm{H},-\mathrm{OCH}_{2} \mathrm{CH}_{2} \mathrm{O}-\right.$ and $\left.-\mathrm{OCH}_{3}\right) \delta 4.6-4.9\left(\mathrm{~m}, 2 \mathrm{H} \mathrm{NCH} \mathrm{CH}_{2} \mathrm{O}\right) \delta 8.7$ $(\mathrm{m}, 1 \mathrm{H}, \mathrm{NCC} H(m$-pyridyl)) $\delta 8.8-9.5(\mathrm{br} \mathrm{s}, 4 \mathrm{H}$, pyrrole) d 9.0-9.2 (m, 2H, NCHCHCH, m-pyridyl and p-pyridyl) d 9.6-9.8 (m, 1H, NCH, o-pyridyl). (UV-vis)

Synthesis of $\mathrm{FeCl}$ Tetrakis-2-(Triethylene Glycol Monomethyl Ether) Pyridyl Porphyrin The iron metallation process was modified from a procedure described by Pasternack et al. (18). FP15 was dissolved in water and 5 eq of ferrous ammonium sulfate was added. The mixture was heated to reflux until the Soret band broadened and $\lambda_{\text {max }}$ shifted from $\lambda=418$ to $\lambda=412 \mathrm{~nm}$. In addition, a broad shoulder appeared at approximately $\lambda=350 \mathrm{~nm}$, which is characteristic of an iron porphyrin, and the number of Q-bands decreased from 4 to 2 . The reaction mixture was cooled, stirred with Bio-Rad AGIX8 ionexchange resin $\left(\mathrm{Cl}^{-}\right.$form) for $2 \mathrm{hr}$, then the resin was filtered off. The solution was neutralized after filtration with saturated $\mathrm{NaHCO}_{3}$. Solvent was stripped and the residue was chromatographed on Sephadex LH-20 In 1:1 $\mathrm{CH}_{3} \mathrm{OH} / \mathrm{H}_{2} \mathrm{O}$. Removal of solvent left FP15 in $65 \%$ yield as a shiny black solid.

\section{Time-Resolved Visible Spectra}

All the time-resolved visible spectra were recorded on a HI-TECH SF-61 DX2 stopped-flow spectrophotometer equipped with a diode array detector (19). The spectral resolution was about $1 \mathrm{~nm}$. Reactions between FP15 and peroxynitrite were singlemixing experiments, performed at $25{ }^{\circ} \mathrm{C}$, and the concentrations presented in all cases are the final concentrations after mixing. The porphyrin solutions were buffered with $50 \mathrm{mM}$ of phosphate buffer, pH 7.4.

\section{Nitration of Fluorescein}

In a typical reaction, $5 \mu \mathrm{M}$ of fluorescein in buffer is reacted with $25 \mu \mathrm{M}$ of peroxynitrite in both the absence and presence of $5 \mu \mathrm{M}$ of FP15. The changes in fluorescein absorbance were measured on HP 8453 Uv-vis spectrophotometer, running HP Chemstation software (Version A.07.01). The yield of nitration was determined by converting absorbance to changes in concentration of fluorescein and nitrated fluorescein, 
using predetermined extinction coefficients. For increased accuracy, the three wavelengths where the largest changes in absorbance occur were used. Also, because the catalyst is bleached to a small extent by peroxynitrite $(<1 \%$ delta OD), the absorbance measurements of fluorescein were adjusted for this small change in the absorbance of the catalyst during the reaction. The yields were calculated based on the initial substrate concentration.

\section{Testing of FP15 in Cell Culture}

The RINm5F insulin-containing beta-cell line (RIN) and the human umbilical vein endothelial cells (HUVEC) were cultured in 96-well plates until confluence as described $(14,20)$. The RIN cells were selected because they are relevant for the primary process of diabetes, the HUVEC cells because of their relevance for cardiovascular dysfunction. In addition, primary mouse thymocytes, a convenient model system for peroxynitrite-induced cell necrosis and apoptosis, were also used as previously described (5). Cells were then exposed to peroxynitrite $(50-600 \mu \mathrm{M})$ in the presence or absence of a 10-min pretreatment with FP15 $(3-30 \mu \mathrm{M})$.

\section{Quantification of Cell Death}

Mitochondrial respiration, a global index of cell viability, was assessed by the reduction of 3-(4, 5-dimethylthiazol-2-yl)-2,5-diphenyltetrazolium bromide (MTT) to formazan as described (14). In thymocytes, apoptosis and necrosis were simultaneously measured by the quantification of annexin staining and cellular propidium iodide uptake using flow cytometry as described (5).

\section{Multiple Low-Dose Streptozotocin Model of Diabetes}

Male BALB/c mice were treated with streptozotocin $(40 \mathrm{mg} / \mathrm{kg}$ ) or vehicle (citrate buffer) IP for 5 consecutive days (21) in the presence or absence of FP15 ( 3 or $10 \mathrm{mg} / \mathrm{kg} / \mathrm{d}$ orally in two divided doses) starting on day 1 . Blood glucose was measured on days 1, 7, 14, and 21 from blood obtained from the tail vein using a one-touch blood glucose meter. Hyperglycemia was defined as nonfasting blood glucose $>200 \mathrm{mg} / \mathrm{dl}$. Samples of pancreas were removed and analyzed for insulin, malon dialdehyde, and myeloperoxidase content, an indicator of neutrophil infiltration as described (21). Furthermore, pancreas sections were excised, fixed in $10 \%$ formaldehyde, and immunohistochemically analyzed for nitrotyrosine formation $(10,12)$.

\section{Development of Diabetes in the Nonobese Diabetic Mice}

Female nonobese diabetic (NOD) mice develop a high incidence of diabetes between the 10th and 25 th weeks of life (12). We have subjected groups of NOD mice to vehicle or FP15 treatment (3 and $10 \mathrm{mg} / \mathrm{kg}$, treatment protocols identical to the streptozotocin model) between the ages of 10 and 25 weeks.

\section{Induction of Diabetic Endothelial and Cardiac Dysfunction}

For the cardiovascular studies, diabetes was induced in male Balb/c mice by a single injection of streptozotocin (200 mg/kg IV) (12). Mice developing severe hyperglycemia (>350 mg/dl) and glucosuria for 2 consequent days were selected and considered diabetic. Six weeks after the injection of streptozotocin, control and diabetic mice received either vehicle or FP15 (10 mg/kg/d orally in two divided doses). Diabetic mice and age-matched controls were killed after 3 weeks after the start of FP15 treatment and subjected to cardiovascular measurements. Analysis of left ventricular performance was measured in anesthetized mice with a Millar microtip catheter transducer as described (22). For the measurement of changes in vascular reactivity, an ex vivo thoracic aorta assay was employed as described (14). In rings precontracted with epinephrine $\left(10^{-6} \mathrm{M}\right)$, relaxation to acetylcholine $\left(10^{-9}\right.$ to $\left.10^{-5} \mathrm{M}\right)$ and sodium nitroprusside $\left(10^{-12}\right.$ to $\left.10^{-5} \mathrm{M}\right)$ was evaluated.

\section{Data Analysis and Presentation}

For the in vitro studies, all values in the figures and text are expressed as mean \pm standard error of the mean of $n$ observations, where $n$ represents the number of wells studied (6-9 wells from two or three independent experiments). Numerical data sets were examined by analysis of variance and Bonferroni's $t$-test. Diabetes incidence was compared using the Chi-square test. A $p$-value less than 0.05 was considered statistically significant.

\section{Results}

Chemical Characterization of FP15

We chose triethylene glycol monomethyl ether as the $\mathrm{N}$-alkylating group for 2-PyP because it satisfied the requirements for bulk and hydrophilicity. Early attempts to alkylate 2-PyP with triethylene glycol monomethyl ether bromide or iodide were not successful; the bromide and iodide were both difficult to synthesize and did not completely alkylate the porphyrin. We synthesized the triethylene glycol monomethyl ether tosylate, and this compound successfully quaternized 2-PyP. The tosylate was also much easier to synthesize, and consistent $70-80 \%$ yields of pure product were obtained. 2-PyP was alkylated in a hot mixture of DMF and tosylate, and the reaction could be followed easily by UV-vis. The Soret band of the porphyrin undergoes a characteristic shift from $\lambda=412$ to $\lambda=418 \mathrm{~nm}$ upon complete alkylation. The tosylate counterions are exchanged for chloride by double precipitation with ammonium hexafluorophosphate and then tetrabutylammonium chloride. The porphyrin thus obtained, tetrakis 2-(triethylene glycol monomethyl ether) pyridyl porphyrin (2-T(PEG3)PyP) could be characterized by ${ }^{1} \mathrm{H}$ NMR and electrospray mass spectrometry. 
Kinetics of Catalytic Peroxynitrite Decomposition by FP15

FP15 $(0-8 \mu \mathrm{M})$ in PBS pH 7.4 was reacted with $\sim 100 \mu \mathrm{M}$ of peroxynitrite in a rapid-mixing stopped flow spectrophotometer as described (17) in PBS pH 7.4 in the absence or presence of $10 \mathrm{mM}$ of bicarbonate. The rate constant of peroxynitrite decay was determined by fitting the 302-nm data to a first-order rate expression. The results were plotted versus the catalyst concentration (Fig. 1). The shape of the rate constant dependence on the catalyst concentration is nonlinear and upward sloping, as observed before for other FeTMPyP-based porphyrins (23). The data indicated that the contribution of $\mathrm{CO}_{2}$-catalyzed peroxynitrite decomposition to its overall decay decreases at higher catalyst concentrations. In fact, at $8 \mu \mathrm{M}$ of catalyst, the presence of $10 \mathrm{mM}$ of bicarbonate has no measurable effect on peroxynitrite decay. This effect is explained by the fact that under these conditions, FP15 outcompetes the reaction with carbon dioxide. Only $5 \%$ of all peroxynitrite reacted with carbon dioxide and $95 \%$ reacted with the catalyst, which at this concentration has a second-order rate constant of $6.25 \times 10^{6} \mathrm{M}^{-1} \mathrm{~s}^{-1}$.

\section{Inhibition of Phenolic Nitration by FP15}

Nitration of fluorescein by peroxynitrite can be used as a sensitive marker for the efficiency of phenolic nitration. Catalysts that can rapidly decompose peroxynitrite without creating nitrating species will

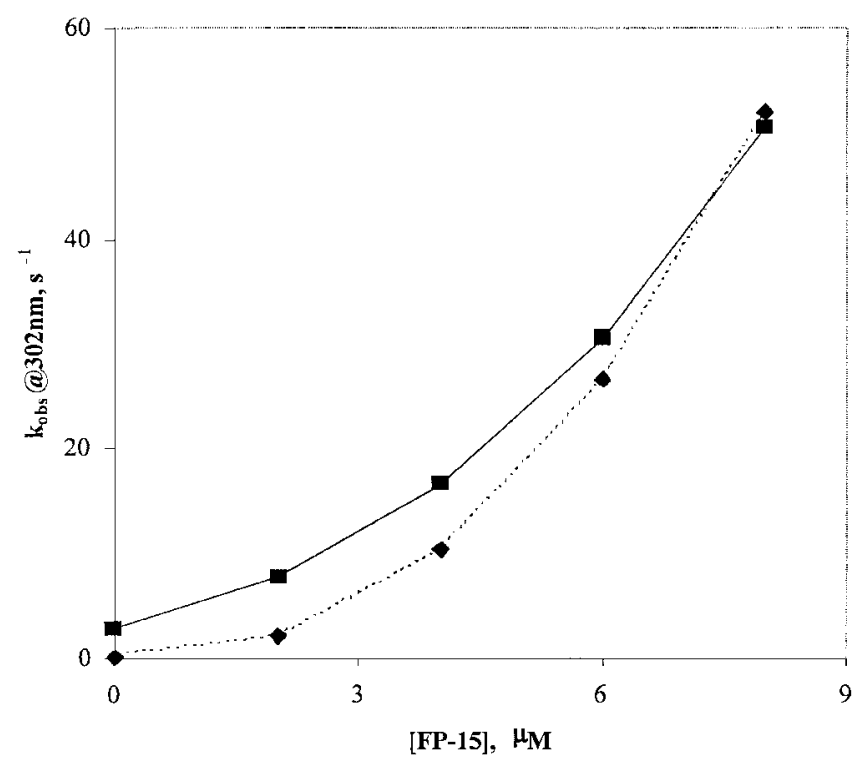

Fig. 1. Determination of $k_{\text {cat }}$ of FP15 toward peroxynitrite decomposition. Reaction was carried out in PBS pH 7.4 in the absence (closed square) or presence (closed diamond) of $10 \mathrm{mM}$ of bicarbonate. Concentration of FP15 was varied 0-8 $\mu \mathrm{M}$, peroxynitrite was maintained at $\sim 100 \mu \mathrm{M}$. FP15 concentration was plotted against the observed rate constant of peroxynitrite decay. $\boldsymbol{K}_{\mathrm{obs}}$ is obtained from first-order fit of absorbance decay at $302 \mathrm{~nm}$. The plot shows a nonlinear dependence that suggests involvement of two distinct reaction pathways, as proposed elsewhere (19).
Table 1. Reduction of tyrosine nitration by FP15 in vitro

\begin{tabular}{lcc}
\hline & $\begin{array}{c}\text { 0.1 M PBS, } \\
\text { pH 7.4 } \\
(\mathbf{I}=\mathbf{0 . 2 6} \text { M) }\end{array}$ & $\begin{array}{c}\text { 0.1 M PBS, } \\
\text { 10 mM HCO3, } \\
\text { pH 7.58, (I = 1.0 M) }\end{array}$ \\
\hline No Catalyst & $41.9 \%$ & $55.1 \%$ \\
Exp. 1 & $4.9 \%$ & $5.7 \%$ \\
Exp. 2 & $6.5 \%$ & $5.6 \%$ \\
Exp. 3 & $5.0 \%$ & $5.2 \%$ \\
& & \\
\hline
\end{tabular}

reduce the level of fluorescein nitration when present in micromolar amounts. The results showed that the presence of $5 \mu \mathrm{M}$ of FP15 decreases the level of fluorescein nitration by peroxynitrite approximately 8 -fold (Table 1 ). Also, the presence of $10 \mathrm{mM}$ of bicarbonate, which reacts relatively fast with peroxynitrite to form peroxynitritocarbonate (a very reactive and unstable intermediate that rapidly decomposes and forms carbonate and nitrate radicals), has very small effect under these conditions.

\section{Cytoprotection by FP15 In Vitro}

Exposure of islet cells, endothelial cells, and thymocytes to peroxynitrite induced a dose-dependent cytotoxicity, with the thymocytes and the islets being most sensitive (Fig. 2). Pretreatment of the cells with FP15 (3-30 $\mu \mathrm{M})$ caused a dose-dependent restoration of cell viability and of the mitochondrial respiration (Fig. 2A). FP15 treatment protected both against peroxynitrite-induced necrosis and apoptosis, as shown in thymocytes by flow cytometric analysis (Fig. 2B).

\section{Role of Peroxynitrite in the Process of Islet Cell Destruction and Diabetes Development}

Because evidence for the formation of peroxynitrite has previously been reported in diabetic islets (12), now we tested whether treatment of streptozotocindiabetic mice with FP15 ameliorates the incidence and severity of diabetes. Oral treatment with FP15 provided a dose-dependent, and-at the highest dose of $10 \mathrm{mg} / \mathrm{kg}$ used-near-complete protection against hyperglycemia, pancreatic beta cell destruction, and diabetes incidence in the multiple lowdose streptozotocin diabetes (Fig. 3). The effects of FP15 were associated with suppression of pancreatic malon dialdehyde levels, consistent with a reduced oxidative stress in the pancreas (e.g., $10 \mathrm{mg} / \mathrm{kg}$ FP15 reduced malon dialdehyde levels in diabetic islets from $653 \pm 54$ to $312 \pm 37 \mathrm{pmol} / \mathrm{mg}$ protein, $p<0.01$, $n=8$; baseline levels amounted to $258 \pm 42 \mathrm{pmol} / \mathrm{mg}$ protein in nondiabetic mice). Myeloperoxidase levels, an indicator of neutrophil infiltration, were unaffected by FP15 treatment (data not shown). FP15 treatment attenuated the tyrosine nitration in the diabetic islets (Fig. 4). 
A.

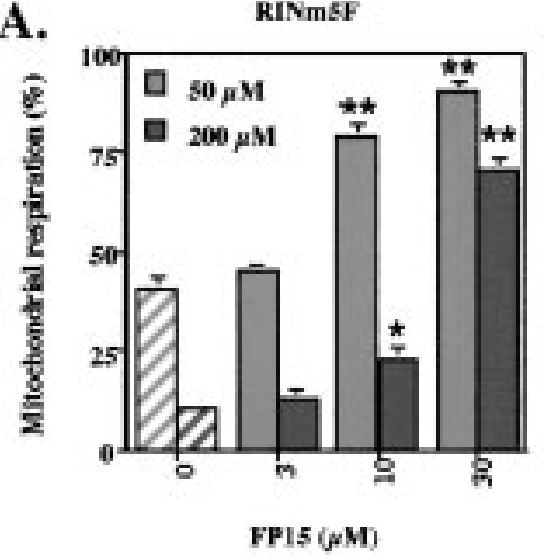

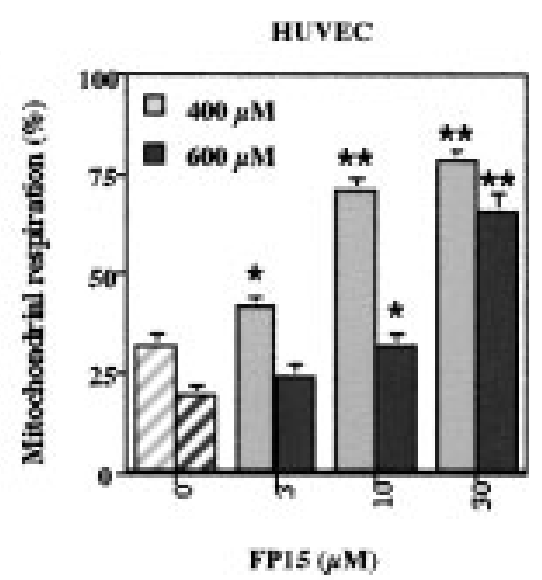

B.

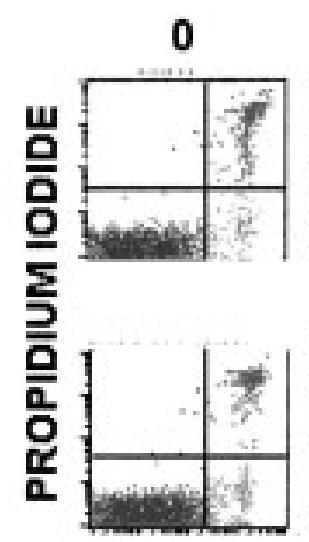

\section{ONOO- $\mu \mathrm{M}$}
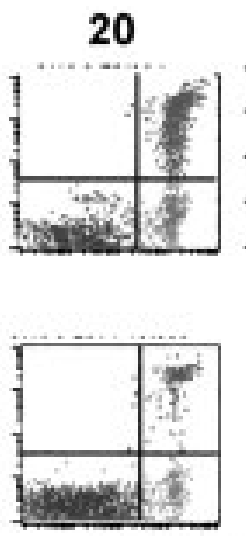

ANNEXIN-FITC
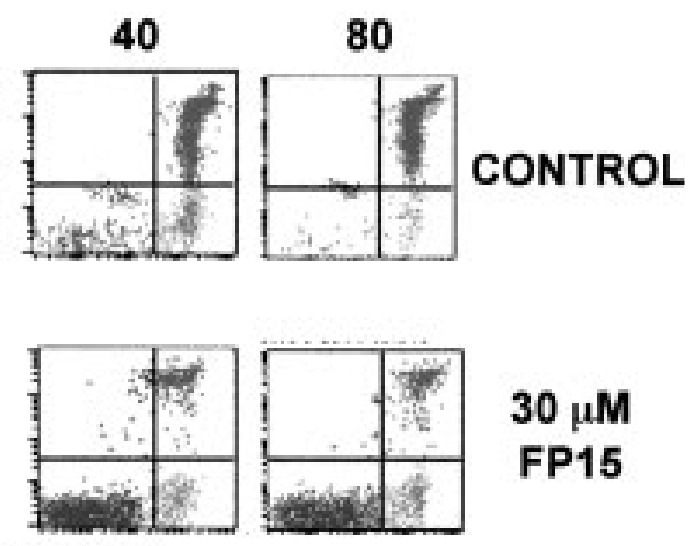

$30 \mu \mathrm{M}$ FP15
Fig. 2. Cytoprotection by FP15. (A) Effect of peroxynitrite (50-600 $\mu \mathrm{M})$ on mitochondrial respiration in RINm5F cells (left panel) and HUVECs (right panel); concentration-dependent restoration of the suppression of mitochondrial respiration by FP15 $(3-30 \mu \mathrm{M})$. *,** represent significant effects of FP15 in peroxynitrite-treated cells $(p<0.05, p<0.01$, respectively); $n=6$ to 9. (B) Cytofluorometric analysis of thymocyte necrosis and apoptosis induced by peroxynitrite. Thymocytes were treated for $4 \mathrm{hr}$ with $20-80 \mu \mathrm{M}$ of peroxynitrite. Cells were then stained with Annexin V-FITC and propidium iodide (PI) and two-color analysis was performed by flow cytometry. During apoptosis, phosphatidylserine becomes exposed on the outer surface of the plasma membrane and can be detected by Annexin-FITC. Necrosis is characterized by the breakdown of plasma membrane integrity that can be measured by the uptake of the cell impermeable dye propidium iodide (5). An increase in the number of apoptotic (Annexin V-FITC single positive, bottom right quadrant) cells as well as necrotic (stained by both Annexin V-FITC and PI, top right quadrant) cells was observed in response to $20-\mu \mathrm{M}$ peroxynitrite treatment, whereas necrotic cells dominate in response to $80-\mu \mathrm{M}$ peroxynitrite. FP15-treated cells were protected against both necrotic and apoptotic cell death, and normal cells (bottom left quadrant) are predominant. Similar results were found in four independent experiments.
Although the multiple low-dose streptozotocin (MLDS) model has a component of immune/inflammatory injury, as well as a chemical (direct oxidant) component, we sought to confirm the effects using another model system, which is generally considered closer to the human autoimmune Type I diabetes. NOD mice provide such a model; the female animals are genetically predisposed and develop diabetes over time. Oral treatment with FP15 provided a marked, significant protection against diabetes onset in the NOD model. For example, at week 25 , diabetes incidence stabilized at $14 / 18$ in the vehicle treated group $(78 \%)$, whereas it was reduced to $4 / 18(22 \%)$ in the FP15 $(10 \mathrm{mg} / \mathrm{kg} / \mathrm{d})$ treated group $(n=18$ animals per group, $p<0.05$ ).

\section{Role of Peroxynitrite in the Development of Diabetic Cardiovascular Complications}

The formation of peroxynitrite has previously been reported in blood vessels and hearts of diabetic subjects (10-13). Therefore, we tested whether treatment of diabetic mice with FP15 ameliorates the development of endothelial dysfunction and diabetic cardiac dysfunction. In these experiments, a single high-dose streptozotocin was used in rats. This protocol is most suitable for the sudden, complete destruction of diabetic islets and produces a rapid-onset, prolonged hyperglycemia (12). Six weeks after the injection of streptozotocin, control and diabetic mice began either vehicle or FP15 (10 mg/kg/d orally) treatment, and were killed 3 weeks later. This delayed start of peroxynitrite decomposition catalyst treatment ensured that the animals received the FP15 treatment at a time when islet cell destruction was already complete and hyperglycemia has stabilized. In this way, we avoided interference of the compound with the primary process of the islet cell destruction, as confirmed by a lack of effect of FP15 on blood glucose concentration in this posttreatment regimen. Although FP15 did not affect blood glucose levels, it provided a marked protection against the loss of endothelium-dependent relaxant ability of the blood vessels (Fig. 5). No differences were seen in the degree of sodium 

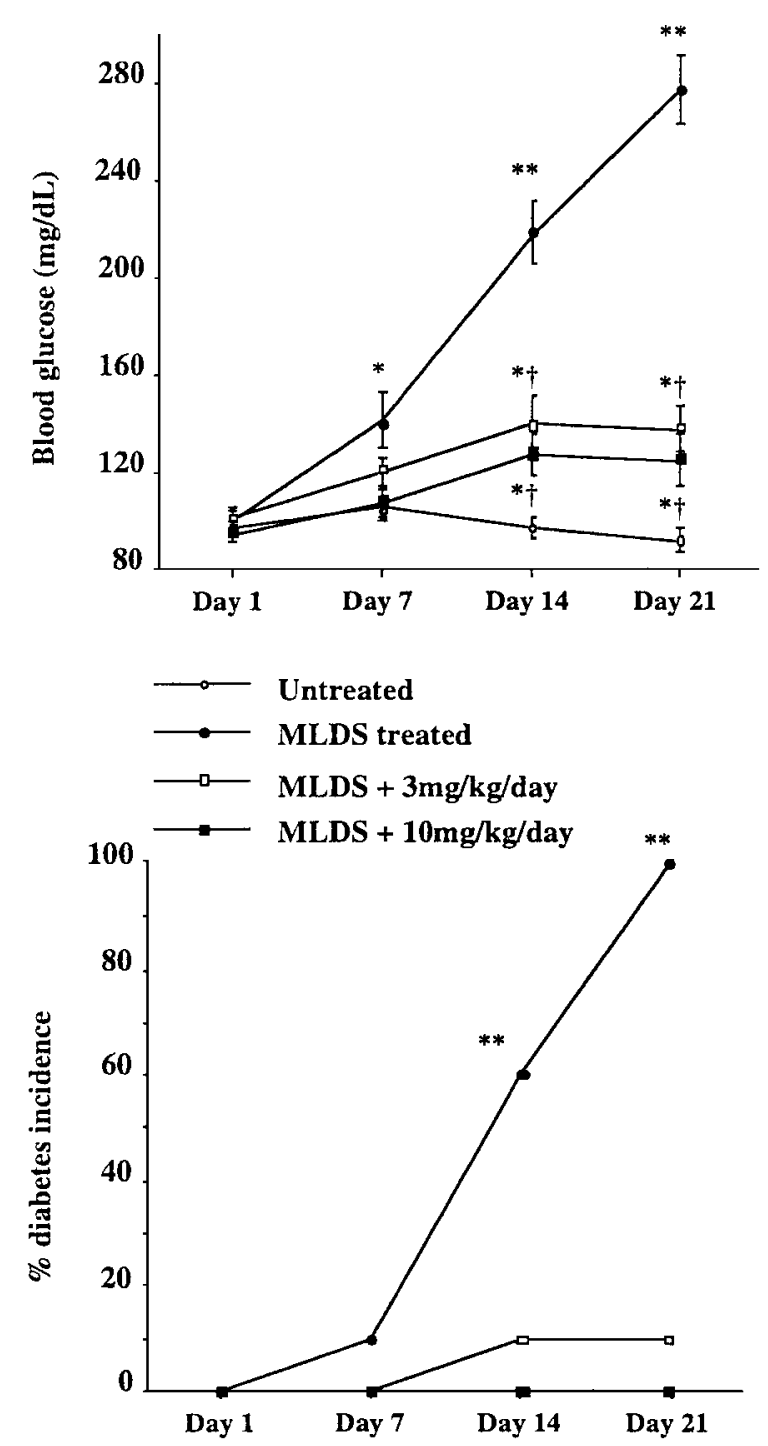

Fig. 3. Dose-dependent effect of FP15 on (top panel) hyperglycemia and (bottom panel) diabetes incidence in male BALB/c mice following treatment with multiple low-dose streptozotocin (MLDS, 18 mice per experimental group). ${ }^{*} p<0.05$ and ${ }^{* *} p<0.01$ in diabetic versus untreated (nondiabetic) mice and ${ }^{+} p<0.05$ in FP15 treated diabetic mice versus vehicle-treated diabetic mice.

nitroprusside-induced endothelium-independent relaxations between experimental groups (data not shown). Diabetes was also characterized by an increase in left ventricular end-diastolic pressure and decrease in heart rate, mean blood pressure, left ventricular systolic pressure, $+\mathrm{dP} / \mathrm{dt}$, and $-\mathrm{dP} / \mathrm{dt}$ (Fig. 6). FP15 improved the depression in left ventricular systolic pressure and diastolic $-\mathrm{dP} / \mathrm{dt}$. Moreover, the elevation of the left ventricular end-diastolic pressure and the decrease of systolic $+\mathrm{dP} / \mathrm{dt}$ were prevented by the peroxynitrite decomposition catalyst inhibitor treatment. FP15 in nondiabetic rats had no significant effects on vascular responsiveness or hemodynamic parameters (Figs. 5 and 6).

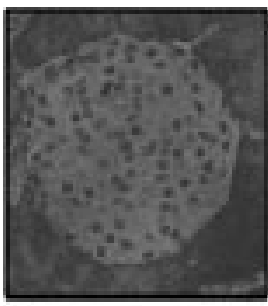

Centrol

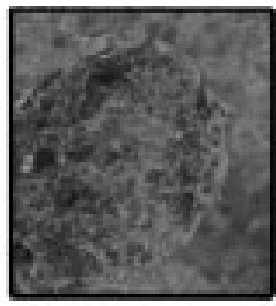

Diabetes

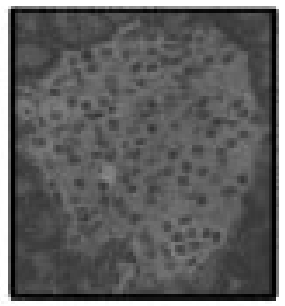

Diabetes+FP15
Fig. 4. Nitrotyrosine immunostaining in the multiple lowdose streptozotocin diabetes model in (A) the pancreas of a control (nondiabetic) mouse, (B) pancreas of a mouse at 14 days of diabetes, and (C) pancreas of an FP15-treated mouse at 14 days of diabetes. Note the marked increase in nitrotyrosine staining in the islets in diabetes, and its amelioration in the FP15-treated animals. Pictures representative of $n=$ 4 to 5 experiments are shown. Original magnification: $\times 40$.

\section{Discussion}

FP15, A Porphyrinic Peroxynitrite Decomposition Catalyst, Protects Against Peroxynitrite-Induced Cytotoxicity

The chemistry and biology of peroxynitrite have been under intense scrutiny since its cytotoxic activity (23-29) was first recognized. This molecule has been implicated in many pathophysiologic conditions, and it has been shown that the body's own systems are ill-equipped to eliminate it (see Introduction and Shi et al. [30]). Metalloporphyrins are of particular interest for this reason; peroxynitrite reacts very efficiently with biological metal centers (18,31-33). If a metalloporphyrin could be introduced into a living system as treatment for peroxynitrite injury, it would be of therapeutic potential. It has recently been shown that certain water-soluble manganese and iron porphyrins show high rates of reaction with peroxynitrite (29).

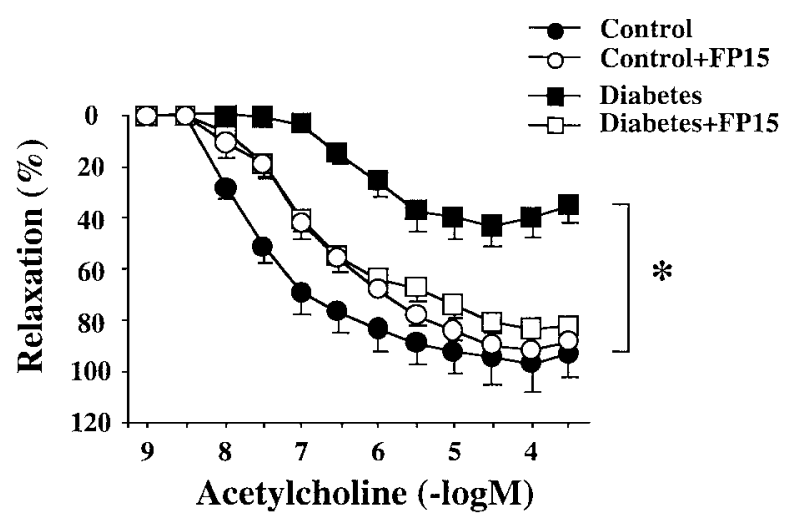

Fig. 5. Reversal of diabetes-induced endothelial dysfunction by FP15 in vascular rings from STZ-diabetic mice. Ach-induced endothelium-dependent relaxation is impaired in rings from diabetic mice, which is markedly improved by FP15 treatment. Each point of the curve represents the mean \pm SEM of 5-7 pairs of experiments in vascular rings. * $p<0.05$ in FP15 treated diabetic mice versus vehicle-treated diabetic mice. 

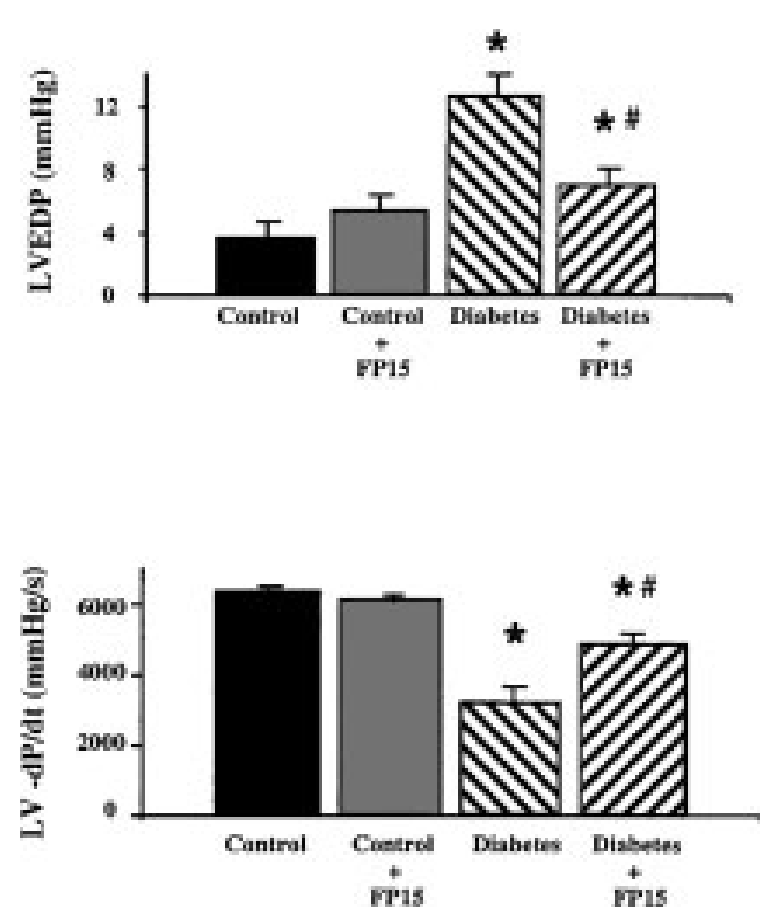

Fig. 6. Reversal of streptozotocin-evoked diabetesinduced diastolic cardiac dysfunction by FP15 in mice. Effect of diabetes (9-10 weeks) and FP15 treatment in diabetic mice on left ventricular end diastolic pressure (LVEDP) and left ventricular $-\mathrm{dp} / \mathrm{dt}(\mathrm{LV}-\mathrm{dp} / \mathrm{dt})$. Results are mean \pm SEM of seven experiments in each group. ${ }^{*} p<0.05$ diabetic animals versus control; $\# p<0.05$ in FP15-treated diabetic mice versus vehicle-treated diabetic mice.

One such porphyrin, iron(III) meso-tetrakis(2, 4,6-trimethyl-3,5-disulfonato) porphine chloride (FeTMPS) has already shown activity at micromolar levels and was shown to attenuate carrageenaninduced paw edema in rats (34). This result, combined with the attractive peroxynitrite turnover rates obtained for the family of pyridyl porphyrins, prompted us to consider a new catalyst based on the pyridyl porphyrin systems.

The novel catalyst FP15 represents an effort to apply results obtained in vitro to biological systems. This catalyst has been designed specifically for pharmacologic use, building on previous knowledge in the field for maximum efficacy. The polyethylene glycol chains attached to the porphyrin provide a hydrophilic environment for peroxynitrite while providing sufficient bulk to hinder deleterious associations between the porphyrin and DNA. It retains the high rate constant for peroxynitrite turnover observed for other iron porphyrin catalysts $(17,21)$, showing that diverse groups may be introduced at the N-pyridyl position and the porphyrin will still retain activity. The shape of the rate constant dependence on the catalyst concentration is nonlinear and upward sloping, and has been observed before for other FeTMPyP-based porphyrins (21). This peculiar curvature gave rise to a reaction mechanism that postulates the involvement of an oxoFe(IV) intermediate in a separate catalytic pathway. The data also indicate that the contribution of $\mathrm{CO}_{2}$-catalyzed peroxynitrite decomposition to its overall decay decreases at higher catalyst concentrations. In fact, at $8 \mu \mathrm{M}$ of catalyst, the presence of $10 \mathrm{mM}$ of bicarbonate has no measurable effect on peroxynitrite decay. This effect is explained by the fact that under these conditions, FP15 outcompetes the reaction with carbon dioxide. Only $5 \%$ of all peroxynitrite reacted with carbon dioxide and $95 \%$ reacted with the catalyst, which at this concentration has a second-order rate constant of $6.25 \times 10^{6} \mathrm{M}^{-1} \mathrm{~s}^{-1}$. As was shown in the stopped flow experiment, discussed above, at this catalyst concentration, FP15 reacts with peroxynitrite at an approximate secondorder rate constant of $3.5 \times 10^{6} \mathrm{M}^{-1} \mathrm{~s}^{-1}$, whereas the corresponding rate constant between carbon dioxide and peroxynitrite is $3 \times 10^{4} \mathrm{M}^{-1} \mathrm{~s}^{-1}$ (35). Under these conditions the concentration of aqueous carbon dioxide is only $\sim 0.23 \mathrm{mM}$, so the flux of peroxynitrite reacting with it instead of with FP15 is approximately $13 \%$, whereas the flux through FP15 is $86 \%$, and only about $0.4 \%$ of peroxynitrite decomposes spontaneously. The fact that FP15 decomposes peroxynitrite directly to nitrate without producing nitrating intermediates, as has been suggested for its analogs (21), is supported by the current findings showing that the nitration of fluorescein is inhibited in its presence. The above rough calculation of peroxynitrite flux illustrates that because only $13 \%$ of peroxynitrite reacts with carbon dioxide, which in absence of catalyst gives $55 \%$ nitration, then the expected nitration yield in the presence of FP15 would be $\sim 7 \%$, which is very similar to the experimentally obtained nitration yield.

Just like with other porphyrins and antioxidants, additional redox properties of the compound on other oxidant species (superoxide, hydrogen peroxide, nitroxyl anion, etc.) are possible. These additional actions may limit the specificity of the compound, and may reduce its utility as a tool to dissect peroxynitrite-mediated pathogenetic processes from processes triggered by these above-mentioned oxidants. On the other hand, such additional actions may extend the therapeutic utility of these agents.

\section{Role of Peroxynitrite in the Pathogenesis of Diabetic Islet Cell Destruction and Hyperglycemia}

As discussed in the Introduction, tyrosine nitration has been previously reported in diabetic islets, and its degree showed a good correlation with the degree of diabetes. In addition, it was previously reported that human islets are extremely sensitive to peroxynitrite toxicity (36). NO synthase inhibitors and the inducible NO synthase knockout mice are protected against diabetes development $(37,38)$. The current report is the first one to directly demonstrate that a peroxynitrite decomposition catalyst ameliorates disease onset and severity, both in a combined chemically 
induced/autoimmune model (the multiple low-dose streptozotocin model) and in the autoimmune mode (NOD mice). Although peroxynitrite has been reported to induce neutrophil adhesion and activation in vitro (39), we did not find evidence for suppressed neutrophil infiltration into the pancreas in FP15treated diabetic mice. This finding is consistent with findings obtained with an earlier generation peroxynitrite decomposition catalyst, 5,10,15,20-tetrakis[4-sulfonatophenyl]-porphyrinato-iron (FeTPPS) in a rat model of splanchnic occlusion-reperfusion injury, where reduced lipid peroxidation, but no change in myeloperoxidase levels, was observed (40).

\section{Role of Peroxynitrite in the Pathogenesis of Diabetic Islet Cell Destruction and Hyperglycemia}

The agonist-induced release of NO from the vascular endothelium plays a crucial role in maintaining the vascular homeostasis by keeping the blood vessels in a constant state of vasodilatation and by preventing platelet and mononuclear cell deposition to the intima. Impairment of the endothelial function has been proposed to predispose to a variety of vascular diseases, including diabetic micro- and macroangiopathy (12). Exposure of blood vessels to peroxynitrite can lead to an impairment of the endotheliumdependent relaxant ability (14). The present study provides direct evidence for the pathogenic role of peroxynitrite in diabetic endothelial dysfunction. The peroxynitrite decomposition catalyst was effective in this model despite the fact that the blood vessels were exposed to continuous, high levels of circulating glucose. In this diabetes model, a complete diabetic endothelial dysfunction develops by 4 weeks $(12,41)$. Thus, the compound not only is able to prevent the development of diabetic endothelial dysfunction, but is also able to restore the function of diabetic blood vessels with established endotheliopathy. The mechanism by which FP15 protects diabetic blood vessels from endothelial dysfunction may involve protection against vascular tyrosine nitration, PARP activation, lipid peroxidation, and multiple other mechanisms; all these mechanisms have previously been linked to diabetic vasculopathy as well as to peroxynitriteinduced vascular injury (2-14).

\section{Role of Peroxynitrite in the Pathogenesis of Diabetic Cardiomyopathy}

Diabetic cardiomyopathy is characterized by complex changes in the mechanical, biochemical, structural, and electrical properties of the heart, which may be responsible for the development of an early diastolic dysfunction and increased incidence of cardiac arrhythmias in diabetic patients (42). The present study demonstrates that streptozotocininduced diabetes in NOD mice and rats was associated with a marked depression of left ventricular function involving both systolic pressure development and relaxation. Importantly, the results presented here document for the first time that the impaired diabetic cardiac function can be reversed by pharmacologic neutralization of peroxynitrite toxicity.

Oxidative stress associated with an impaired antioxidant defense status may play a critical role in subcellular remodeling, calcium-handling abnormalities, and subsequent diabetic cardiomyopathy (42). Consistent with this idea, significant nitrotyrosine formation was reported in cardiac myocytes from myocardial biopsy samples obtained from diabetic and diabetic-hypertensive patients (43) and in a mouse model of streptozotocin-induced diabetes (44). The present study provides direct evidence for the pathogenetic role of peroxynitrite in the development of the contractile function in the heart. The mechanism by which FP15 protects diabetic hearts from dysfunction may involve protection against vascular and myocardial tyrosine nitration, PARP activation, lipid peroxidation, and multiple other mechanisms; all these mechanisms have previously been linked to diabetic cardiomyopathy as well as to peroxynitrite-induced cardiac injury. Additional mechanisms of peroxynitrite-mediated diabetic cardiac dysfunction may include inhibition of myofibrillar creatine kinase (45) and of succinylCoA:3-oxoacid CoA-transferase (46).

\section{Conclusions and Implications}

The current studies describe the synthesis and characterization of FP15, a potent novel peroxynitrite decomposition catalyst. Treatment of diabetic animals with FP15 demonstrated the involvement of peroxynitrite in the pathogenesis of the primary disease, as well as in the development of vascular and myocardial dysfunction. Additional studies demonstrate the neuroprotective (47) and cardioprotective $(48,49)$ effects of FP15, as well as its potent beneficial effects in lung reperfusion models (50) and in murine models of rheumatoid arthritis and inflammatory bowel disease (51). The current results support the view that peroxynitrite-neutralizing agents may be of interest in the experimental therapy of various pathophysiologic conditions associated with peroxynitrite generation.

\section{Acknowledgments}

We are grateful for support of this research through grants from the National Institutes of Health (R01GM60915 and R01HL71246 to C. S. and R01GM36928 to J. T. G.).

\section{References}

1. Beckman JS, Beckman TW, Chen J, Marshall PA, Freeman BA. (1990) Apparent hydroxyl radical production by peroxynitrite: implications for endothelial injury from nitric oxide and superoxide. Proc. Natl. Acad. Sci. U. S. A. 87: 1620-1624.

2. Ischiropoulos H, Zhu L, Chen J, et al. (1992) Peroxynitritemediated tyrosine nitration catalyzed by superoxide dismutase. Arch. Biochem. Biophys. 298: 431-437. 
3. Estevez AG, Radi R, Barbeito L, Shin JT, Thompson JA, Beckman JS. (1995) Peroxynitrite-induced cytotoxicity in PCl2 cells: evidence for an apoptotic mechanism differentially modulated by neurotrophic factors. J. Neurochem. 65: 15431550.

4. Szabó C, Zingarelli B, O'Connor M, Salzman AL. (1996) DNA strand breakage, activation of poly (ADP-ribose) synthetase, and cellular energy depletion are involved in the cytotoxicity of macrophages and smooth muscle cells exposed to peroxynitrite. Proc. Natl. Acad. Sci. U. S. A. 93: 1753-1758.

5. Virág L, Scott GS, Marmer D, Cuzzocrea S, Salzman AL, Szabó C. (1998) Peroxynitrite-induced thymocyte apoptosis: the role of caspases and poly (ADP-ribose) synthetase (PARS) activation. Immunology 94: 345-355.

6. Estevez AG, Spear N, Manuel SM, et al. (1998) Nitric oxide and superoxide contribute to motor neuron apoptosis induced by trophic factor deprivation. J. Neurosci. 18: 923-939.

7. Beckman JS, Koppenol WH. (1996) Nitric oxide, superoxide, and peroxynitrite: the good, the bad, and ugly. Am. J. Physiol. 271: C1424-C1437.

8. Szabó C. (1996) The pathophysiological role of peroxynitrite in shock, inflammation, and ischemia-reperfusion injury. Shock 6: 79-88.

9. Greenacre SA, Ischiropoulos H. (2001) Tyrosine nitration: localisation, quantification, consequences for protein function and signal transduction. Free Radic. Res. 34: 541-581.

10. Suarez-Pinzon WL, Szabó C, Rabinovitch A. (1997) Development of autoimmune diabetes in NOD mice is associated with the formation of peroxynitrite in pancreatic islet beta-cells. Diabetes 46: 907-911.

11. Kastenbauer S, Koedel U, Becker BF, Pfister HW. (2002) Oxidative stress in bacterial meningitis in humans. Neurology 58: 186-191.

12. Soriano FG, Virág L, Jagtap P, et al. (2001) Diabetic endothelial dysfunction: the role of poly(ADP-ribose) polymerase activation. Nature Med. 7: 108-113.

13. Thuraisingham RC, Nott CA, Dodd SM, Yaqoob MM. (2000) Increased nitrotyrosine staining in kidneys from patients with diabetic nephropathy. Kidney Int. 57: 968-972.

14. Szabó C, Cuzzocrea S, Zingarelli B, O'Connor M, Salzman AL. (1997) Endothelial dysfunction in a rat model of endotoxic shock. Importance of the activation of poly (ADP-ribose) synthetase by peroxynitrite. J. Clin. Invest. 100: 723-735.

15. Villa LM, Salas E, Darley-Usmar VM, Radomski MW, Moncada S. (1994) Peroxynitrite induces both vasodilatation and impaired vascular relaxation in the isolated perfused rat heart. Proc. Natl. Acad. Sci. U. S. A. 91: 2383-2387.

16. Ferdinandy P, Panas D, Schulz R. (1999) Peroxynitrite contributes to spontaneous loss of cardiac efficiency in isolated working rat hearts. Am. J. Physiol. 276: H1861-H1867.

17. Digerness SB, Harris KD, Kirklin JW, et al. (1999) Peroxynitrite irreversibly decreases diastolic and systolic function in cardiac muscle. Free Radic. Biol. Med. 27: 1386-1392.

18. Pasternack RF, Gillies BS, Stromsted JP. (1978) Substitution reactions of a water-soluble metalloporphyrin with azide and 1,1,3,3-tetramethyl-2-thiourea. Bioinorg Chem. 8: 33-44.

19. Shimanovich R, Groves JT. (2001) Mechanisms of peroxynitrite decomposition catalyzed by FeTMPS, a bioactive sulfonated iron porphyrin. Arch. Biochem. Biophys. 387: 307-317.

20. Mabley JG, Cunningham JM, John N, Di Matteo MA, Green IC. (1997) Transforming growth factor beta l prevents cytokine-mediated inhibitory effects and induction of nitric oxide synthase in the RINm5F insulin-containing beta-cell line. J. Endocrinol. 155: 567-575.

21. Mabley JG, Suarez-Pinzon WL, Hasko G, et al. (2001) Inhibition of poly (ADP-ribose) synthetase by gene disruption or inhibition with 5-iodo-6-amino-1,2-benzopyrone protects mice from multiple-low-dose-streptozotocin-induced diabetes. Br. J. Pharmacol. 133: 909-919.

22. Liaudet L, Szabo E, Timashpolsky L, Virag L, Cziraki A, Szabo C. (2001) Suppression of poly (ADP-ribose) polymerase activation by 3-aminobenzamide in a rat model of myocardial infarction: long-term morphological and functional consequences. Br. J. Pharmacol. 133: 1424-1430.

23. Lee J, Hunt JA, Groves JT. (1998) Manganese porphyrins as redox-coupled peroxynitrite reductases. J. Am. Chem. Soc. 120: 6053-6061.

24. Radi R, Beckman JS, Bush KM, Freeman BA. (1991) Peroxynitrite-induced membrane lipid peroxidation: the cytotoxic potential of superoxide and nitric oxide. Arch. Biochem. Biophys. 288: 481-487.

25. Klebanoff SJ. (1993) Reactive nitrogen intermediates and antimicrobial activity: role of nitrite. Free Radic. Biol. Med. 14: 351-360.

26. Estevez AG, Crow JP, Sampson JB, et al. (1999) Induction of nitric oxide-dependent apoptosis in motor neurons by zincdeficient superoxide dismutase. Science 286: 2498-2500.

27. Bohle DS. (1998) Pathophysiological chemistry of nitric oxide and its oxygenation by-products. Curr. Opin. Chem. Biol. 2: 194-200.

28. Groves JT. (1999) Peroxynitrite: reactive, invasive and enigmatic. Curr. Opin. Chem. Biol. 3: 226-235.

29. Greenacre SA, Ischiropoulos H. (2001) Tyrosine nitration: localisation, quantification, consequences for protein function and signal transduction. Free Radic. Res. 34: 541-581.

30. Shi X, Rojanasakul Y, Gannett P, et al. (1994) Generation of thiyl and ascorbyl radicals in the reaction of peroxynitrite with thiols and ascorbate at physiological pH. J. Inorg. Biochem. 56: 77-86.

31. Balavoine GG, Geletti YV, Bejan D. (1997) Catalysis of peroxynitrite reactions by manganese and iron porphyrins. Nitric Oxide 1: 507-521.

32. Lee J, Hunt JA, Groves JT. (1997) Rapid decomposition of peroxynitrite by manganese porphyrin-antioxidant redoxcouples. Bioorg. Med. Chem. Lett. 7: 2913-2918.

33. Groves JT, Lee J, Marla S. (1997) Detection and characterization of an oxo-manganese $(\mathrm{V})$ porphyrin complex by rapidmixing stopped-flow spectrophotometry. J. Am. Chem. Soc. 119: 6269-6273.

34. Salvemini D, Wang ZQ, Stern MK, Currie MG, Misko TP. (1998) Peroxynitrite decomposition catalysts: therapeutics for peroxynitrite-mediated pathology. Proc. Natl. Acad. Sci. U. S. A. 95: 2659-2663.

35. Lymar SV, Hurst JK. (1996) Carbon dioxide: physiological catalyst for peroxynitrite-mediated cellular damage or cellular protectant? Chem. Res. Toxicol. 9: 845-850.

36. Delaney CA, Tyrberg B, Bouwens L, Vaghef H, Hellman B, Eizirik DL. (1996) Sensitivity of human pancreatic islets to peroxynitrite-induced cell dysfunction and death. FEBS Lett. 394: 300-306.

37. Suarez-Pinzon WL, Mabley JG, Strynadka K, Power RF, Szabo C, Rabinovitch A. (2001) An inhibitor of inducible nitric oxide synthase and scavenger of peroxynitrite prevents diabetes development in NOD mice. J. Autoimmun. 16: 449-455.

38. Flodstrom M, Tyrberg B, Eizirik DL, Sandler S. (1999) Reduced sensitivity of inducible nitric oxide synthase-deficient mice to multiple low-dose streptozotocin-induced diabetes. Diabetes 48: 706-713.

39. Zouki C, Zhang SL, Chan JS, Filep JG. (2001) Peroxynitrite induces integrin-dependent adhesion of human neutrophils to endothelial cells via activation of the Raf-1/MEK/Erk pathway. FASEB J. 15: 25-27.

40. Cuzzocrea S, Misko TP, Costantino G, et al. (2000) Beneficial effects of peroxynitrite decomposition catalyst in a rat model of splanchnic artery occlusion and reperfusion. FASEB J. 14: 1061-1072.

41. Soriano FG, Mabley JG, Pacher P, Liaudet L, Szabó C. (2001) Rapid reversal of the diabetic endothelial dysfunction by pharmacological inhibition of poly(ADP-ribose) polymerase. Circ. Res. 89: 684-691.

42. Sowers JR, Epstein M, Frohlich ED. (2001) Diabetes, hypertension, and cardiovascular disease: an update. Hypertension 37: 1053-1059.

43. Frustaci A, Kajstura J, Chimenti C, et al. (2000) Myocardial cell death in human diabetes. Circ. Res. 87: 1123-1132. 
44. Kajstura J, Fiordaliso F, Andreoli AM, et al. (2001) IGF-1 overexpression inhibits the development of diabetic cardiomyopathy and angiotensin II-mediated oxidative stress. Diabetes 50: 1414-1424.

45. Mihm MJ, Coyle CM, Schanbacher BL, Weinstein DM, Bauer JA. (2001) Peroxynitrite induced nitration and inactivation of myofibrillar creatine kinase in experimental heart failure. Cardiovasc. Res. 49: 798-807.

46. Turko IV, Marcondes S, Murad F. (2001) Diabetes-associated nitration of tyrosine and inactivation of succinyl-CoA:3oxoacid CoA-transferase. Am. J. Physiol. 281: H2289-H2294.

47. Zhang X, Chen J, Graham SH, et al. (2002) Intranuclear localization of apoptosis-inducing factor and large scale DNA fragmentation after traumatic brain injury in rats and in neuronal cultures exposed to peroxynitrite. J. Neurochem. 82: 181-191.
48. Bianchi C, Wakiyama H, Faro R, et al. (2002) A novel peroxynitrite decomposition catalyst (FP-15) reduces heart infarct size in a model of acute ischemia-reperfusion. Ann. Thorac. Surg. (in press).

49. Pacher P, Liaudet L, Bai P, Virág L, Mabley JG, Szabó C. (2002) A potent peroxynitrite decomposition catalyst, FP15, protects against the development of doxorubicin-induced heart failure. FASEB J. 16: Al77 (abstract).

50. Naidu BV, Krishnadasan B, Fraga C, et al. (2002) The critical role of reactive nitrogen species in lung ischemia reperfusion injury. J. Heart Lung Transplant. 21: 135 (abstr).

51. Mabley JG, Liaudet L, Pacher P, Southan GJ, Salzman AL, Szabó C. (2002) Beneficial effects of the peroxynitrite decomposition catalyst FP15 in murine models of arthritis and colitis. Mol. Med. 8: 581-590. 